\title{
Evaluation of several measures of canopy openness as predictors of photosynthetic photon flux density in deeply shaded conifer-dominated forest understory
}

\author{
José-Luis Machado and Peter B. Reich
}

\begin{abstract}
The ability to accurately estimate light levels in shaded environments is important for understanding plant adaptations to shade. This study evaluates the effectiveness of three rapid methods of estimating the long-term integrated percentage of above-canopy photosynthetic photon flux density (PPFD) in a deeply shaded conifer-dominated forest understory. These methods included ( $i$ ) hemispherical canopy photography, (ii) hemispherical sensors (LAI-2000), and (iii) instantaneous \%PPFD. Transmitted PPFD was continuously measured starting in June and ending in November using photodiodes at 60 measurement points ranging from 1 to 50\% PPFD. Measurements from all methods were positively and linearly related to the mean daily \%PPFD measured for two different periods of the year (foliage on and foliage off). However, the strength of the relationship and closeness to a 1:1 fit was weaker for the hemispherical photograph technique. During the foliage-on period, the hemispherical sensor (LAI-2000) explained 90\% of the variation in mean daily \%PPFD, while the instantaneous \%PPFD and hemispherical photography explained 88 and $67 \%$, respectively. Moreover, when examining low-light conditions only ( $<6 \%$ PPFD), hemispherical photographs failed to detect differences in \%PPFD, while the other two techniques were nearly as effective in low light as across the entire light gradient.
\end{abstract}

Résumé : La capacité d'estimer avec précision les niveaux d'intensité lumineuse dans les environnements ombragés est importante pour la compréhension de l'adaptation des plantes à l'ombre. Cette étude évalue l'efficacité de trois méthodes rapides d'estimation du pourcentage intégré à long terme de la densité du flux des photons photosynthétiques (DFPP) au-dessus de la canopée qui est transmis au sous-étage fortement ombragé d'une forêt dominée par les conifères. Ces méthodes incluent $(i)$ la photographie hémisphérique de la canopée, (ii) les capteurs hémisphériques LAI-2000 et (iii) le pourcentage instantané de la DFPP. La DFPP transmise a été mesurée continuellement à partir de juin jusqu'en novembre en utilisant des photodiodes à 60 points de mesurage, allant de 1 à $50 \%$ de la DFPP. Les mesures faites avec toutes les méthodes sont reliées de façon linéaire et positive à la moyenne journalière du pourcentage de la DFPP déterminée pour deux périodes différentes de l'année (avec et sans feuillage). Toutefois, la force de cette relation et sa proximité d'un rapport $1: 1$ est plus faible dans le cas de la photographie hémisphérique. Durant la période avec feuillage, le capteur hémisphérique LAI-2000 expliquait $90 \%$ de la variation de la moyenne journalière du pourcentage de la DFPP, tandis que le pourcentage instantané de la DFPP et la photographie hémisphérique en expliquaient 88 et $67 \%$, respectivement. Bien plus, lorsqu'on examine seulement des conditions de faible luminosité ( $<6 \%$ de la DFPP), les photographies hémisphériques ne détectent pas les différences dans le pourcentage de la DFPP, alors que les deux autres techniques sont presque aussi efficaces à faible luminosité qu'à travers tout le gradient de luminosité.

[Traduit par la Rédaction]

\section{Introduction}

Light availability influences many important biological processes such as plant growth and succession (Cannell and Grace 1993). The ability to accurately estimate light in

Received August 11, 1998. Accepted April 19, 1999.

J.-L. Machado, ${ }^{1}$ and P.B. Reich. Department of Forest Resources, University of Minnesota, 1530 Cleveland Avenue North, St. Paul, MN 55108, U.S.A.

${ }^{1}$ Corresponding author. Present address: Laboratorio de Ecología de Poblaciones, Departamento de Biología, Pontificia Universidad Javeriana, Cra. 7a No. 43-82, SantaFe de Bogotá, Colombia. e-mail: jmachado@tc.umn.edu deeply shaded understories is important for understanding plant adaptations to shade, which is a key factor underlying the dynamics of forest succession (Shirley 1943). Estimation of light environments beneath vegetation canopies is very challenging because of the spatial and temporal variability of light (Baldocchi and Collineau 1994). Direct measures using radiation sensors can be effective but are expensive, cumbersome, and impractical for multiple-point sampling. Thus, we need simpler indirect methods to accurately estimate the light environment in which plants occur and grow. At present, the indirect methods commonly used to estimate light environments are (i) hemispherical photograph analysis (Pearcy 1989; Cannell and Grace 1993; Rich et al. 1993) and (ii) optical methods that use modified light sensors such as ceptometers, plant canopy analyzers, and other instruments 
(Welles 1990; Welles and Norman 1991). Several authors have reported positive relationships between hemispherical photography, estimates of PPFD, and direct measurements of PPFD but only for a small set of light conditions or without taking into consideration the total incoming radiation above the canopy (Easter and Spies 1994; Rich et al. 1993 but see Gendron et al. 1998). A third method, developed by Messier and Puttonen 1995, proposed that instantaneous percent above-canopy PPFD ((PPFD in understory/PPFD above canopy) $\times 100$ ) under completely overcast conditions, measured with radiation sensors, can also be a good estimate of the mean daily percent above-canopy PPFD over the course of a day and under all sky conditions (Parent and Messier 1996). Recently, Gendron et al. (1998) and Comeau et al. (1998), working in deciduous forests, have reported that all three methods are indeed equally good at estimating light availability during the growing season over a broad range of $\%$ PPFD (0-100\%).

The purpose of this study was to evaluate the effectiveness of three different methods of estimating daily PPFD and mean daily percent above-canopy PPFD in coniferous forest understories in northern Minnesota. We used the same three methods tested by Gendron et al. (1998) and Comeau et al. (1998): (i) hemispherical photography, (ii) hemispherical sensor, and (iii) instantaneous percent above-canopy PPFD. The hemispherical sensor was the LAI-2000 plant canopy analyzer (Li-Cor Inc., Lincoln, Neb.), which has been used extensively to estimate leaf area index (Gower and Norman 1991; Fassnacht et al. 1994). The first objective was to test the methods across a broad light gradient at different seasons of the year to evaluate the effect of changes in canopy structure due to leaf phenology (before and after leaf abscission) on the three indirect indices. The second objective was to evaluate the capability of these indices in estimating light availability in low-light environments $(<6 \%$ PPFD).

\section{Materials and methods}

The study area was located at the University of Minnesota's Cloquet Forestry Center, in Cloquet, MN (46 $40^{\circ} \mathrm{N}$. $92^{\circ} 30^{\prime} \mathrm{W}$.). Two sites less than $0.5 \mathrm{~km}$ apart were selected. The first site was an overstocked stand (basal area $85.3 \mathrm{~m}^{2} \cdot \mathrm{ha}^{-1}$, density 1455 trees/ha) with a white pine (Pinus strobus L.) overstory and a subcanopy of red maple (Acer rubrum L.) and balsam fir (Abies balsamea (L.) Mill.). The understory was dominated by beaked hazel (Corylus cornuta Marsh.). The second site was a shelterwood stand (basal area $42.4 \mathrm{~m}^{2} \cdot \mathrm{ha}^{-1}$, density 255 trees/ha) composed mainly of red pine (Pinus resinosa Ait.) and white pine overstory trees. No major subcanopy was present. Its understory was patchy, composed mainly of scattered beaked hazel, some red maple trees, and young balsam fir trees. Trees reached a height of 15-20 m in both stands. The stands provided a range of canopy gaps varying in shape and size. Sampling points within each stand were selected to span a large range of light environments.

\section{Direct methods of estimating PPFD and daily percent above-canopy PPFD}

\section{Integrated PPFD}

A large opening created by a clearcut, less than $1 \mathrm{~km}$ away from our understory sample points, was used to estimate the PPFD incident on a horizontal surface above the canopy, using a quantum sensor (LI-190s, Li-Cor Inc., Lincoln, Neb.). The PPFD levels in the understory sample points were measured with gallium arsenide photodiodes (G1118, Hamamatsu Corporation Bridgewater, N.J.), which are sensitive to light in the range of photosyntethic active radiation (PAR; 400-700 nm; Pontailler 1990). The photodiodes were mounted and leveled at $0.5 \mathrm{~m}$ above the ground. All measurements were taken every $60 \mathrm{~s}$ and stored as 10-min averages on data-loggers (CR-10, Campbell Scientific, Logan, Utah). Daily percent above-canopy PPFD was estimated as (daily sum of PPFD in the understory sample points)/(daily sum of PPFD in the large clearing) $\times 100$. PPFD was calculated using measurements only between 07:00 and 17:00 to reduce experimental error due to the poor calibration of gallium arsenide sensors at low light readings, rather than using measurements for the full photoperiod. The data were collected from August 23 until November 9, 1995, and from June 13 until August 22, 1996. We lost 45 of 150 days of measurements for all 60 sensors because of damage to the sensor measuring the above-canopy PPFD. All sensors were calibrated individually against factory-calibrated quantum sensors (LI190s, Li-Cor Inc., Lincoln, Neb.). We report the daily percent above-canopy PPFD averaged for all days grouped in two periods, foliage-on and foliage-off (before and after leaf abscission, respectively), regardless of sky conditions (hereafter called mean daily \%PPFD).

\section{Indirect methods estimating daily percent above-canopy PPFD}

\section{Instantaneous percent above-canopy PPFD}

We calculated instantaneous percent above-canopy PPFD (hereafter called instantaneous \%PPFD) for the same 60 measurement points on one completely overcast day during the foliage-on period (July 31, $n=60$ ) and another completely overcast day during the foliage-off period (October 30, $n=60$ ) of 1995 between 07:00 and 10:00. PPFD measurements were collected using paired quantum sensors (LI-190s, Li-Cor Inc., Lincoln, Neb.) attached to dataloggers (LI-1000, Li-Cor Inc., Lincoln, Neb.). One sensor was left in the large clearcut, and the other was placed at the measurement point.

\section{LAI-2000 plant canopy analyzer}

Diffuse noninterceptance measured by the LAI-2000 plant canopy analyzer indicates the fraction of the sky that is not blocked by the foliage, branches, or stems (hereafter called canopy openness). The sensor measures radiation (short wave <490 nm) instantaneously at five separate zenith angles $\left(0-74^{\circ}\right)$ simultaneously and compares it to a similar measurement made simultaneously above the canopy (Li-Cor Inc. 1992). This measurement is analogous to the instantaneous \%PPFD (see above) but uses a different kind of sensor. We measured canopy openness during the foliage-on period (July 31 and August 3) and foliage-off period (October 30) of 1995. All measurements were taken when the sky was uniformly overcast or $1 \mathrm{~h}$ after dawn and $1 \mathrm{~h}$ before dusk. We used one LAI2000 at each measurement point (forest understory) while another paired unit simultaneously measured open sky values in a large clearcut. We report here the values above $60^{\circ}$ of zenith because the contribution of larger zenith angles is minimal because of the height of the canopy and penumbral effects (Kabakoff and Chazdon 1996). In addition, this reduction in field view allowed us to better compare the LAI-2000 results with those obtained with the hemispherical photography analyzes.

\section{Hemispherical photography}

Hemispherical photographs were taken above each measurement point in the forest understory using black and white film (Kodak Tri-X Pan 400 ASA Eastman Kodak, Rochester, N.Y.) with a 
Canon 7.5-mm hemispherical lens and a Canon AE-1 camera. All hemispherical photographs were taken August 4 and 5, 1995 (foliageon), under completely overcast days using a red filter to increase the contrast between the sky and vegetation. No data is available for the foliage-off period. The camera was leveled at $0.5 \mathrm{~m}$ above the ground and oriented so that the top of the photographs was pointing north. The photographs were analyzed using the software WINPHOT, version 6 (ter Steege 1996) after the images were digitized from negatives (CoolScan, Nikon, Melville, N.Y.). Analyses were performed using standard overcast sky (SOC) in which the illumination of a point in the sky at zenith angle is three times as bright as that near the horizon. The threshold level for each image was selected by comparison with the enlarged print of the negative. In most of the photographs taken in deeply shaded points, the area above $60^{\circ}$ of zenith was usually black. Thus, canopy openness was calculated for a subcircle of $60^{\circ}$ of zenith to minimize the influence of underexposed areas and to allow comparisons with measurements from the LAI-2000 (see above). Estimates of mean daily $\%$ PPFD from hemispherical photography were calculated as global site factor $\left(\mathrm{GSF}=\left[\left(T_{\mathrm{dif}} \times P_{\mathrm{dif}}\right)+\left(T_{\mathrm{dir}} \times P_{\mathrm{dir}}\right)\right] \times 100\right)$ following the relationship established by many authors (see Anderson 1964; Rich et al. 1993; Canham 1988), where $T_{\text {dif }}$ is the diffuse site factor (proportion of diffuse PPFD under the canopy relative to that above the canopy), $T_{\text {dir }}$ is the direct site factor (proportion of direct PPFD under the canopy relative to that above the canopy), and $P_{\text {dif }}$ and $P_{\text {dir }}$ are the proportions of incident PPFD received above the canopy as either diffuse sky radiation or direct radiation, respectively. Values for $P_{\text {dif }}$ and $P_{\text {dir }}$ were set to 0.5 based on previously published data (Canham et al. 1990). GSF values were obtained by averaging 12 days during the foliage-on months at 10- to 12-day intervals to cover the period starting in May 1 and ending in September 30 .

\section{Statistical analyses}

The relationships between direct (mean daily percent abovecanopy PPFD) and indirect methods (percent canopy openness, LAI-2000; percent canopy openness and GSF, hemispherical photography; and instantaneous percent above-canopy PPFD, LI-190) were evaluated using regression analyses. Separate analyses were performed according to time of the year, which was defined as foliage-off period (after broad-leaved species dropped their leaves, autumn season) starting October 5, and foliage-on period (summer season), from June 13 to September 25. The data from the two stands were combined for regression analysis after we found no significant differences at $p<0.05$ in slopes or intercepts of relationships examined for each stand separately.

In this paper, regression analysis is used as a tool to describe linear relationships among variables and is not intended to test the dependency among the dependent and independent variables studied. The latter can only be accomplished with independent estimates of measurement errors for the independent variable, which we cannot calculate (Fuller 1987). Evaluating the measurement error of each of the indirect techniques was beyond the scope of this study, but previous research has shown very good agreement among measurements for canopy openness measured with the LAI2000 (Welles 1990; M.F. Tobin, personal communication).

Because of the lack of normality or homogeneity of variances we also used the nonparametric Spearman rank correlation coefficient (SAS Institute Inc. 1995) to evaluate the relationships between mean daily \%PPFD and the indirect measurements of canopy openness (LAI-2000 and hemispherical photography), instantaneous \%PPFD, and GSF calculated with hemispherical photography (Sokal and Rohlf 1995). All the relationships were evaluated for the foliage-on period and two ranges of light environments: full range of \%PPFD (0-50\%) and a subset of \%PPFD limited to very low light environments $(0-6 \%)$. Relations between measured \%PPFD and instantaneous measures (LAI-2000 and instantaneous \%PPFD) were also analyzed for the foliage-off period.

\section{Results and discussion}

\section{Indirect versus direct methods of estimating percent above-canopy PPFD}

All three indices showed a linear relationship with the mean daily \%PPFD (Fig. 1). Foliage-on and foliage-off canopy openness measured with the LAI-2000 had the strongest correlations with mean daily \%PPFD (Figs. $1 a$ and $1 b$ ). No significant differences were found between the slopes for the two periods of the year $(p>0.87)$. The slopes of the regressions indicated a nearly proportional relationship between canopy openness measured with the LAI-2000 and mean daily \%PPFD at different times of the year. However, the intercepts were significantly different $(p<0.026)$ from one another and from zero ( $95 \%$ confidence interval for both regressions $0.18-3.02$ ). Canopy openness measured with the LAI-2000 is, therefore, a good surrogate of mean daily $\%$ PPFD in deeply shaded conifer-dominated forest. Similar results have been reported in boreal deciduous forest understories (Comeau et al. 1998; Gendron et al. 1998), and millet crop and a shrub fallow in West Africa (Hanan and Begue 1995).

Methodological and technical concerns regarding the use of LAI-2000 plant canopy analyzer have been reported elsewhere (Welles 1990; Welles and Norman 1991; Gower and Norman 1991; Fassnacht et al. 1994; Comeau et al. 1998; Gendron et al. 1998). Technical problems include the assumption that the distribution of light in the sky at a particular point is homogeneous azimuthally when in actuality it is not (Canham et al. 1990; Stadt et al. 1997). However, our measurements integrated direct and diffuse PPFD and included all possible sky conditions (i.e., overcast and clear days) for an entire growing season. These results lead us to conclude that canopy openness measured with the LAI-2000 is a useful tool for the rapid assessment of light environments and can serve as a surrogate for \%PPFD in a deeply shaded conifer-dominated forest type.

A significant linear relationship was also found between mean daily \%PPFD and instantaneous \%PPFD for foliage on and foliage off (Figs. 1 $e$ and Fig. 1 $f$ ). However, significant differences were found between the slopes $(p<0.005)$; the fits, especially during foliage on, were far from a 1:1 line. Several authors have reported a similar relationship among mean daily \%PPFD and instantaneous \%PPFD but only during the foliage-on period (Parent and Messier 1996; Comeau et al. 1998; Gendron, et al. 1998). Better correlations between mean daily \%PPFD and instantaneous \%PPFD have been found after increasing the measurement time for the instantaneous measurement of \%PPFD from 1 min to averages over 1-6 h (Comeau et al. 1998).

Mean daily \%PPFD also showed a positive relationship with hemispherical photography estimates of canopy openness (Fig. 1c) and GSF (Fig. 1d). Hemispherical photographs explained only $61-67 \%$ of the variation in mean daily \%PPFD, while the instantaneous \%PPFD and hemispherical sensor (LAI-2000) explained 88 and 90\%, respectively. Several authors have reported similar or better 
Fig. 1. Relationship among different indices of light availability and empirically measured mean daily percent above-canopy PPFD during two times of the year: foliage on (upper panels) and foliage off (bottom panels). The indices are canopy openness measured with the LAI-2000 for $(a)$ foliage on $(n=60, y=0.26+1.0 x)$ and $(b)$ foliage off $(n=60, y=2.92+1.01 x)$; $(c)$ canopy openness calculated from hemispherical photography for foliage on $(n=60, y=0.69+0.79 x)$; $(d)$ GSF calculated from hemispherical photography for foliage on $(n=60, y=-1.4+0.9 x)$; and instantaneous percent above-canopy PPFD measured with radiation sensors for $(e)$ foliage on $(n=60, y=0.57+1.28 x)$ and $(f)$ foliage off $(n=60, y=2.53+1.05 x)$. Each point represents the mean daily percent above-canopy PPFD for all the days included ( $n=84$ for foliage on and $n=21$ for foliage off). The dotted line represents the $1: 1$ relationship.

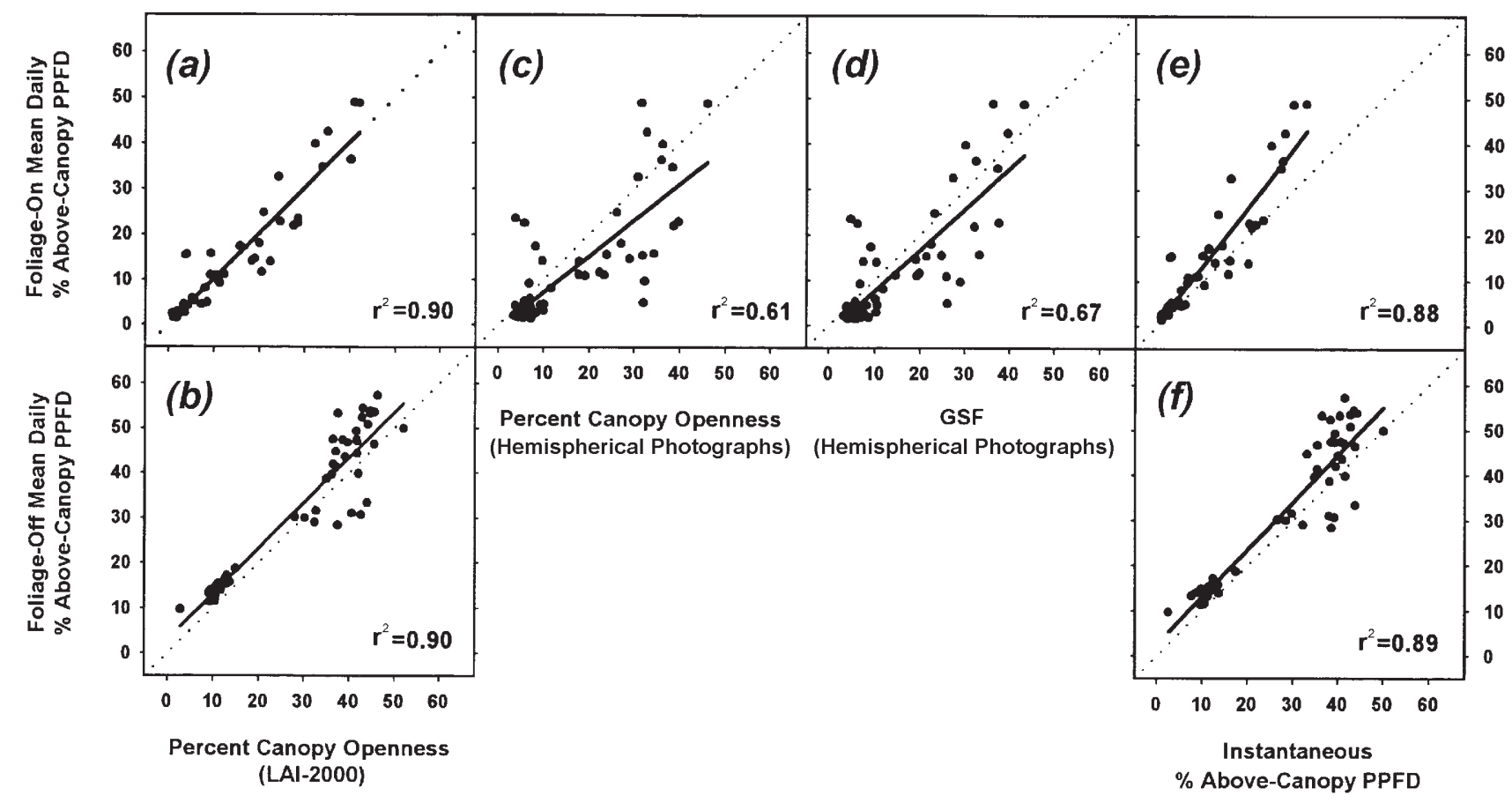

Table 1. Spearman rank correlation coefficients among different direct and indirect measurements of light availability for the full $(0-50 \%)$ and reduced range $(0-6 \%)$ of PPFD.

\begin{tabular}{|c|c|c|c|c|c|c|c|c|}
\hline \multirow[b]{2}{*}{ Measurement } & \multicolumn{2}{|c|}{$\begin{array}{l}\text { Measured mean } \\
\text { daily \%PPFD }\end{array}$} & \multicolumn{2}{|c|}{$\begin{array}{l}\text { Measured } \\
\text { instantaneous } \\
\% \text { PPFD }\end{array}$} & \multicolumn{2}{|c|}{ Calculated GSF } & \multicolumn{2}{|c|}{$\begin{array}{l}\text { Canopy openness } \\
\text { LAI-2000 }(\%)\end{array}$} \\
\hline & $0-50 \%$ & $0-6 \%$ & $0-50 \%$ & $0-6 \%$ & $0-50 \%$ & $0-6 \%$ & $0-50 \%$ & $0-6 \%$ \\
\hline Instantaneous \%PPFD & $0.96 *$ & $0.88 *$ & & & & & & \\
\hline Calculated GSF & $0.74 *$ & 0.23 & $0.69 *$ & 0.09 & & & & \\
\hline Canopy openness (\%; LAI-2000) & $0.96^{*}$ & $0.88 *$ & $0.99 *$ & $0.97 *$ & $0.69 *$ & 0.09 & & \\
\hline
\end{tabular}

Note: Values are for the foliage-on season, and all sky conditions are included for the calculation of \%PPFD.

$* P<0.05$.

correlation for GSF (Rich et al. 1993; Easter and Spies 1994; Comeau et al. 1998; Gendron et al. 1998).

\section{Indirect methods versus mean daily percent above- canopy PPFD under low-light environments}

Given the nonlinear response of photosynthesis and seedling survival to light levels (Pearcy et al. 1987; Walters and Reich 1996), it is important to accurately assess light availability in moderate to deep shade. Light levels beneath closed-canopy forest are often in the range from 1 to $3 \%$ PPFD and in small gaps from 5 to $10 \%$ PPFD (Canham et al. 1990). In low-light environments, defined here arbitrarily as points with less than $6 \%$ PPFD, light estimates calculated from hemispherical photography (canopy openness and GSF) could not detect any differences in mean daily \%PPFD (Figs. $2 b$ and $2 c$, Table 1). In general, the indices calculated from hemispherical photography lost their descriptive power in low-light environments, while canopy openness measured with the LAI-2000 and instantaneous \%PPFD maintained the relationships previously found for the full range of light environments (Figs. 1 and 2, Table 1).

While our results are based on a limited sample and must be interpreted with caution, there seems to be a lack of resolution in low light in the relationship between mean daily $\%$ PPFD and both canopy openness and GSF calculated from hemispherical photographs (Figs. 1 and 2, Table 1). Roxburgh 
Fig. 2. Relationship among different indices of light availability and empirically measured mean daily percent above-canopy PPFD for low light environments (<6\% PPFD). The indices are $(a)$ canopy openness measured with LAI-2000 for foliage on $(n=31, y=0.60+$ $0.83 x)$; (b) canopy openness calculated from hemispherical photography for foliage on $(n=31, y=1.81+0.16 x)$; $(c)$ GSF calculated from hemispherical photography for foliage on $(n=31, y=1.81+0.17 x)$; and $(d)$ instantaneous percent above-canopy PPFD measured with radiation sensors for foliage on $(n=31, y=0.85+1.07 x)$. Each point represents the mean daily percent above-canopy PPFD for all the days included ( $n=84$ for foliage on). The dotted line represents the 1:1 relationship.

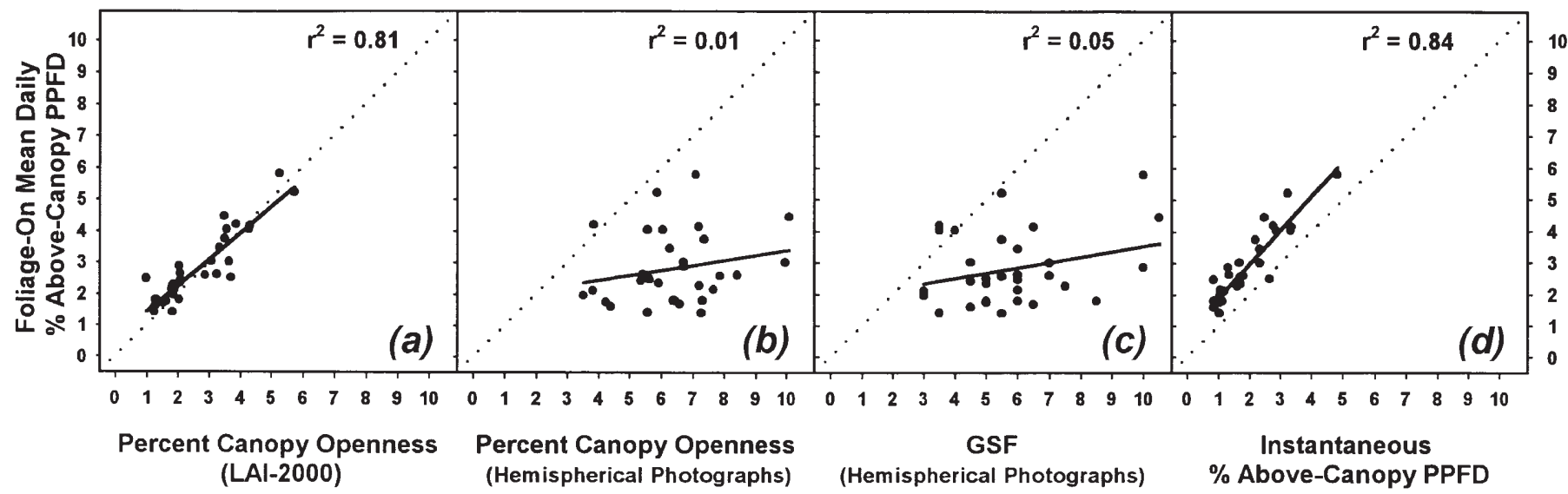

Fig. 3. Relationship between canopy openness measured on July 31 and October 30 (foliage on and foliage off, respectively) with LAI-2000 and monthly changes in measured mean daily percent above-canopy PPFD (upper panels) and PPFD (bottom panels). Mean daily percent above-canopy PPFD and mean daily PPFD were measured for foliage-on months ( $a$ and $c$, respectively) that included June $(\boldsymbol{O})$, July $(\bigcirc)$, August $(\boldsymbol{\nabla})$, and September $(\nabla)$ and foliage-off months $(b$ and $d$, respectively)) that included October $(\boldsymbol{\square})$ and November $(\square)$. The dotted line represents the 1:1 relationship.

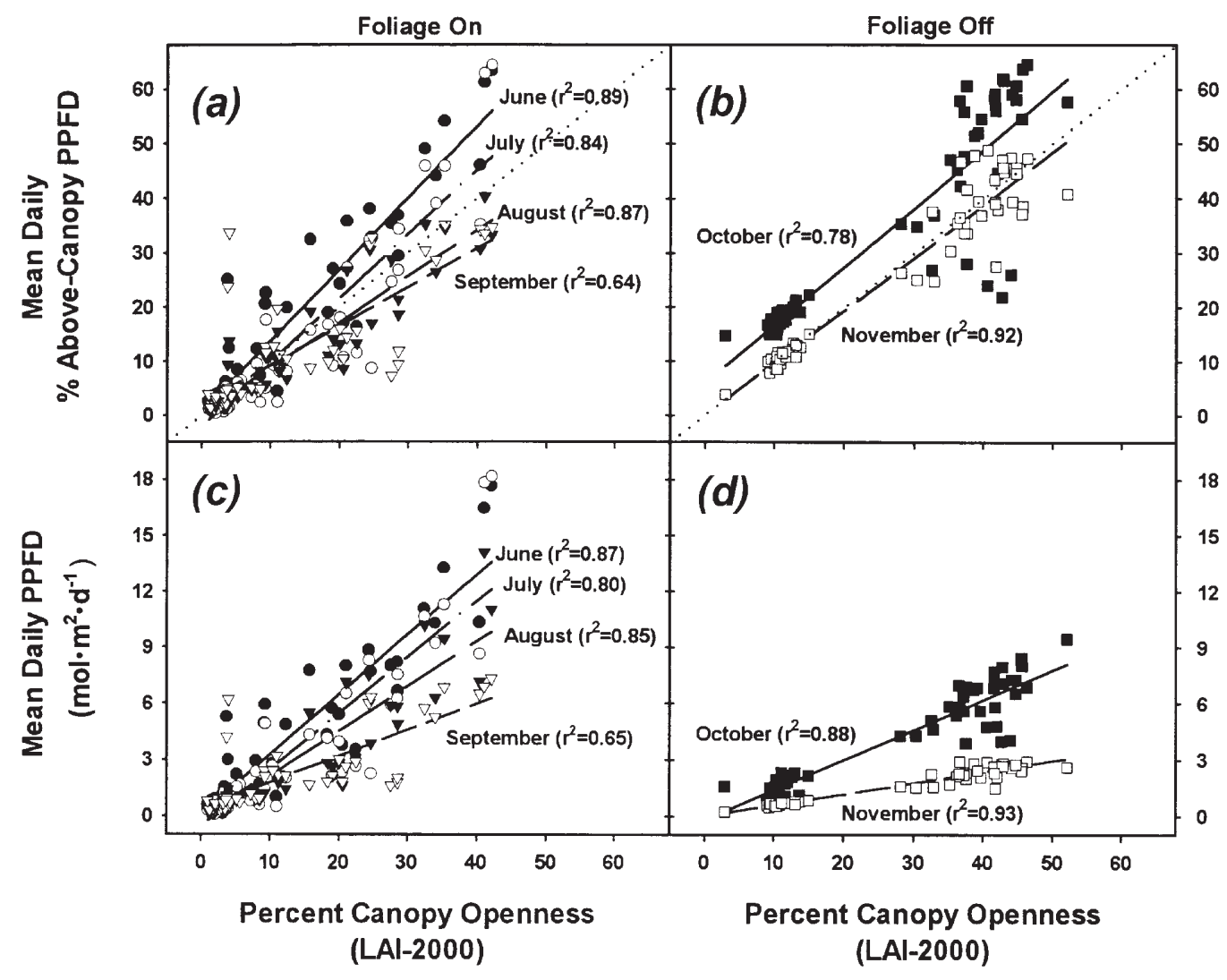

and Kelly (1995) have found similar results. They reported that hemispherical photography could not detect any variation in light below 3\% canopy openness. Rich et al. (1993) reported better but still weak correlations $(r=0.24-0.44)$ between predicted and measured PPFD for low light environments (1-10\% PPFD).

Analysis of hemispherical photographs is very sensitive to errors from sources such as photographic quality (changes in 
contrast, threshold analysis; see Whitmore et al. 1993) and operator analysis. We ran a simple test of the robustness of hemispherical photography by digitizing all our photographs at three previously defined thresholds: two different constant values and one for which the threshold was adjusted for each photograph based on the enlarged print. The coefficient of variation of the mean $(\mathrm{CV})$ for these three analyses decreased from $40 \%$ at points with less than $10 \%$ canopy openness to $15 \%$ at points with higher canopy openness (data not shown). This implies that small changes in threshold could have a large effect on calculated canopy openness when canopy openness is low and might help explain the loss of resolution of hemispherical photographs (see also Roxburgh and Kelly 1995).

\section{Seasonal changes of mean daily PPFD or \% PPFD and LAI-2000 canopy openness}

It is also important to evaluate seasonal changes in the relationship between mean daily PPFD $\left(\mathrm{mol} \cdot \mathrm{m}^{-2}\right.$ per day) or $\%$ PPFD and canopy openness measured with the LAI-2000 at one point in time. On a monthly basis, mean daily $\%$ PPFD was linearly and significantly related to canopy openness measured with LAI-2000 (Figs. $3 a$ and 3b), even though single measurements of canopy openness were taken only once during foliage on (July 31 and August 3) and foliage off (October 30). For the foliage-on period, canopy openness measured with the LAI-2000 overestimated mean daily \%PPFD in August and September but underestimated mean daily \%PPFD measured in June and July (Fig. 3a). For the foliage-off period, canopy openness overestimated mean daily \%PPFD measured in November (Fig. 3b). Thus, LAI2000 measurements for a specific month will approach a 1:1 relationship with \%PPFD for the date in which the LAI2000 measurements were collected. Similarly, mean daily PPFD (mol $\cdot \mathrm{m}^{-2}$ per day) shows a positive and significant relationship with LAI-2000 canopy openness, but there is a decline in absolute values from June to September (foliage on) and October to November (foliage off) following the change in the sun azimuth (Figs. $3 c$ and $3 d$ ). It is clear and not surprising that the relationship between canopy openness and PPFD changes over time.

\section{Conclusions}

The data obtained in the present study lead us to the following conclusions.

(i) Indirect methods such as canopy openness measured with the plant canopy analyzer LAI-2000 are good surrogates of mean daily \%PPFD within the deeply shaded understories in conifer forest of northern Minnesota.

(ii) Light availability expressed as mean daily PPFD and $\%$ PPFD for different months and over different periods of the year before and after leaf abscission were significantly correlated with one-time measurements of canopy openness measured with the LAI-2000, and the relationship is near 1:1 for the month closest to the date of measurement.

(iii) Our observations support the previous results obtained through the use of instantaneous \%PPFD as an index of mean daily \%PPFD (Parent and Messier 1996) in both conifer (this study) and broadleaf-dominated forest (Comeau et al. 1998; Gendron et al. 1998).

(iv) Finally, when working in deeply shaded environments the use of hemispherical photographs should be carefully evaluated. More measurements are needed to draw generalizations on the applicability of canopy openness measurements across different forest types.

\section{Acknowledgements}

This research was part of a Ph.D. dissertation at the Department of Forest Resources, University of Minnesota. The Wilderness Research Foundation, the National Science Foundation, and the F.B. Hubacheck Sr. Endowment at the University of Minnesota provided funding. Thanks are due to the Cloquet Forestry Center staff at the University of Minnesota for their invaluable logistical support, to Keith Wrage for providing the algorithms to calculate percent canopy openness for different zenith angles, and to Hans ter Steege for providing the latest version of WINPHOT. Review comments provided by Michael F. Tobin, Michael B. Walter, Elizabeth M. Svenson, Christian Messier, and one anonymous reviewer are gratefully acknowledged.

\section{References}

Anderson, M.C. 1964. Studies of the woodland light climate I. The photographic computation of light conditions. J. Ecol. 52: 2741.

Baldocchi, D., and Collineau, S. 1994. The physical nature of solar radiation in heterogeneous canopies: spatial and temporal attributes. In Exploitation of environmental heterogeneity by plants. Edited by M.M. Caldwell and R.W. Pearcy. Academic Press, San Diego, Calif. pp. 21-72.

Canham, C.D. 1988. Growth and canopy architecture of shadetolerant trees: response to canopy gaps. Ecology, 69: 786-795.

Canham, C.D., Denslow, J.S., Platt, W.J., Runkle, J.R., Spies, T.A., and White, P.S. 1990. Light regimes beneath closed canopies and tree-fall gaps in temperature and tropical forest. Can. J. For. Res. 20: 620-631.

Cannell, M.G.R., and Grace, J. 1993. Competition for light: detection, measurement, and quantification. Can. J. For. Res. 23: 1969-1979.

Comeau, P.G., Gendron, F., and Letchford, T. 1998. A comparison of several methods for estimating light under a paper birch mixedwood stand. Can. J. For. Res. 28: 1843-1850.

Easter, M.J., and Spies, T.A. 1994. Using hemispherical photography for estimating photosynthetic photon flux density under canopies and in gaps in Douglas-fir forests of the Pacific Northwest. Can. J. For. Res. 24: 2050-2058.

Fassnacht, K.S., Gower, S.T., Norman, J.M., and Mcmurtrie, R.E. 1994. A comparison of optical and direct methods for estimating foliage surface area index in forests. Agric. For. Meteorol. 71: 183-207.

Fuller, W.A. 1987. Measurement error models. John Wiley \& Sons, New York.

Gendron, F., Messier, C., and Comeau, P.G. 1998. Comparison of various methods for estimating the mean growing season percent photosynthetic photon flux density in forest. Agric. For. Meteorol. 92: 55-70

Gower, S.T., and Norman, J.M. 1991. Rapid estimation of leaf area index in conifer and broad-leaf plantations. Ecology, 72: 18961900 . 
Hanan, N.P., and Begue, A. 1995. A method to estimate instantaneous and daily intercepted photosynthetically active radiation using a hemispherical sensor. Agric. For. Meteorol. 74: 155168.

Kabakoff, R.P., and Chazdon, R.L. 1996. Effects of canopy species dominance on understorey light availability in low-elevation secondary forest stands in Costa Rica. J. Trop. Ecol. 12: 779788.

LI-COR Inc. 1992. Instruction manual: LAI-2000 plant canopy analyzer. Li-Cor Inc., Lincoln, Neb.

Messier, C., and Puttonen, P. 1995. Spatial and temporal variation in the light environment of developing Scots pine stands: the basis for a quick and efficient method of characterizing light. Can. J. For. Res. 25: 343-354.

Parent, S., and Messier, C. 1996. A simple and efficient method to estimate microsite light availability under a forest canopy. Can. J. For. Res. 26: 151-154.

Pearcy, R.W. 1989. Radiation and light measurements. In Plant physiological ecology: field methods and instrumentation. Edited by R.W. Pearcy, J. Ehleringer, H.A. Mooney, and P.W. Rundel. Chapman \& Hall, New York. pp. 97-116.

Pearcy, R.W., Bjorkman, O., Caldwell, M.M., Keeley, J.E., Monson, R.K., and Strain, B.R. 1987. Carbon gain by plants in natural environments. BioScience, 37: 21-29.

Pontailler, J.Y. 1990. A cheap quantum sensor using a gallium arsenide photodiode. Funct. Ecol. 4: 591-596.

Rich, P.M., Clark, D.B., Clark, D.A., and Oberbauer, S.F. 1993. Long-term study of solar radiation regimes in a tropical wet forest using quantum sensors and hemispherical photography. Agric. For. Meteorol. 65: 107-127.
Roxburgh, J.R., and Kelly, D. 1995. Uses and limitations of hemispherical photography for estimating forest light environments. N.Z. J. Ecol. 19: 213-217.

SAS Institute Inc. 1995. JMP. Statistics and graphics guide, version 3.1 edition. SAS Institute Inc, Cary, N.C.

Shirley, H.L. 1943. Is tolerance the capacity to endure shade? J. For. 41: 339-345.

Sokal, R.R., and Rohlf, F.J. 1995. Biometry. 3rd ed. W.H. Freeman \& Co., New York.

Stadt, K., Lanhausser, S.M., and Stewart, J.D. 1997. Comment: the effects of direct-beam light on overcast-day estimates of light availability. Can. J. For. Res. 27: 272-274

ter Steege, H. 1996. WINPHOT 5: a program to analyze vegetation indices, light and light quality from hemispherical photographs. Tropenbos-Guyana Progamme, Georgetown, Guyana.

Walters, M.B., and Reich, P.B. 1996. Are shade tolerance, survival, and growth linked? Low light and nitrogen effects on hardwood seedlings. Ecology, 77: 841-853.

Welles, J.M. 1990. Some indirect methods of estimating canopy structure. Remote Sens. Rev. 5: 31-43.

Welles, J.M., and Norman, J.M. 1991. Instrument for indirect measurement of canopy architecture. Agron. J. 83: 818-825.

Whitmore, T.C., Brown, N.D., Swaine, M.D., Kennedy, D., Goodwinbailey, C.I., and Gong, W.K. 1993. Use of hemispherical photographs in forest ecology - measurement of gap size and radiation totals in a Bornean tropical rain forest. J. Trop. Ecol. 9: 131-151. 